Kauko, J. \& Wieland, W.: The Contingent Sense-Making of Contingency:

Epistemologies of Change in Comparative Education, published in

Comparative Education Review 62(2), pp. 157-177.

Copyright $\odot 2018$ Comparative and International Education Society.

Available at https://doi.org/10.1086/696819

Featured Article

\title{
The Contingent Sense-Making of Contingency: Epistemologies of Change in Comparative Education
}

JAAKKO KAUKO AND WIELAND WERMKE

In this article we set out to broaden the scope of comparative education in relation to change. Following what various scholars have already shown, we argue that the world we are exploring is contingent, as too is comparative research, reflecting particular epistemological perspectives. We use this dual focus on contingency and analyze the differences among epistemological understandings of change in a strategic sample of three theoretical traditions in comparative education: borrowing and lending (specifically crossnational attraction), the world culture approach, and the functional-cum-configurational model. We argue that the borderlines of the different traditions emerge from their different epistemological starting points, relating to how they cope with complexity and resulting in different methodological consequences. We conclude that comparative education should both be more aware of the contingency of its sense-making and bolder in theorizing complex contexts.

\section{Introduction}

In this article, we analyze how various comparative education approaches explain change on the basis of their different epistemological assumptions. The main way to do this in comparative education has been in relation to the context of space and time. We argue that while these two factors are key to understanding change, we also need to gain a better understanding of contingency. Change is always contingent, and the contingency of the world encompasses the research itself. To gain an understanding of what this actually means, we engage in analyzing the epistemological starting points of some research traditions in the comparative education field.

Indeed, there have been convincing steps toward a spatial and temporal renarration of comparative education theories (Nóvoa and Yariv-Mashal 2003;

We would like to thank, in particular, Barbara Schulte, and Nelli Piattoeva for their valuable comments on earlier versions of the manuscript. We are also very grateful for the careful reading and comments from the anonymous reviewers, and the help of the editors. This work has been supported by the Academy of Finland (grant number 273871) and the Swedish Research Council (grant number 2015-01448).

Received May 10, 2016; revised December 19, 2016, and June 21, 2017; accepted July 1, 2017; electronically published March 23, 2018

Comparative Education Review, vol. 62, no. 2.

(C) 2018 by the Comparative and International Education Society. All rights reserved.

$0010-4086 / 2018 / 6202-0005 \$ 10.00$ 
Cowen 2009, 963). Researchers criticize theoretical and methodological nationalism (Werner and Zimmermann 2006; Kettunen 2011) and demand a reunderstanding of space in terms of fluid scales (Robertson et al. 2002) - such as the glocal and glonacal (Marginson and Rhoades 2002) and transnational (e.g., Djelic and Sahlin-Andersson 2006) — or of their use in different cultural contexts (Lahelma and Gordon 2010). In addition, the debates regarding space and place and reorienting toward networks, connections, and flows (Larsen and Beech 2014) or policyscapes (Carney 2009) are becoming more prominent. There have been numerous calls for different historical approaches to comparative education (Kazamias 2009; Kallo 2012; Jokila et al. 2015), in terms of transitologies (Cowen 2002) and periods of time as the passing of an opportune moment for change (Simola et al. 2017), for instance, and for rehighlighting the history of the previously marginalized (Tikly 2001, 152) or understanding history as postcolonial "failed historicity" (Ahmed 2000, 10). Even with this less than exhaustive sample, it is clear that comparative education is not short of theories that attempt to reconceptualize time and space.

This reunderstanding time and space further complicates research. In other words, in taking "time and space" not only as a flag term in the sense put forward by Koselleck ([1979] 2004), meaning an ideological statement that states nothing more than that education needs a context, but with the genuine aim to understand its actual impact on education, we bring to the fore contingent features of not only the research of the context but also the research itself.

The question of context has fostered the development of some prominent schools of thought. There are three theoretical approaches that have produced a large corpus of research, and that tend to be seen as mutually exclusive. These perspectives are borrowing and lending (Steiner-Khamsi 2004, 2012), the world culture approach (Meyer et al. 1997; Meyer and Ramirez 2003), and systems theory (Schriewer 2003).

Regardless of the areas in which they disagree, these three theoretical traditions also have commonalities. According to Steiner-Khamsi (2012), Schriewer was one of the early wave of authors from the borrowing and lending tradition, the commonalities of which, according to Waldow (2012), reflect to some extent the idea of externalization, a concept originating from the Luhmannian tradition. The world culture approach and systems analysis share some goals in trying to understand the world society (Schriewer 2000, 312). Then again, Steiner-Khamsi understands the idea of globalization in borrowing and lending as being "diametrically opposed to neoinstitutionalist explanations of isomorphism” (Steiner-Khamsi and Stolpe 2006; SteinerKhamsi 2010, 332). The main criticism of the world culture approach is that it presupposes an advanced industrial world toward which all other contexts should converge (Steiner-Khamsi and Stolpe 2006) and does not actively seek to explore the actual heterogeneity of educational models and practices found 
in the world, thereby bringing about a falsification problem (Waldow 2012, 414). Another issue in this critique is that the approach does not take into account local adaptations and reformulations of world cultures (Waldow 2012), that it is retrospective and teleological, and obsessed with the nation-state (Nóvoa et al. 2003, 14-15).

In and outside these three traditions there is a large body of poststructuralist or postfoundational (Metha and Ninnes 2003) comparative research, boosted before the new millennium (Ninnes and Burnett 2003) with postcolonialist (Ahmed 2000; Joseph 2009), postmodernist (Paulston 1999; Popkewitz 2005), and postcomparatist (Broadfoot 2003; Lawn and Ozga 2012) contributions. This corpus relates itself to the mentioned three approaches, since its "post"-positioning takes the modernist, often intellectually nationalistic, westernized perspective of the three approaches as a reference for their critique. It is also conscious, in line with Foucault, of the power and knowledge effects of the comparative education research itself. ${ }^{1}$ While the general orientation is identifiable, it is harder to make an accurate description of a collection of post-structuralist research due to its self-reflexivity and emphasis on the contextual importance. However, this is exactly the feature that provides an important challenge to the whole comparative education field. Paulston $(2000,363)$ imagines how "explanations of reality are increasingly understood as human constructions" and that a new understanding is up for grabs for "those comparative educators who learn to negotiate (navigate?) the new spaces of knowledge."

It is important to note that as part of the comparative education research community, we see our task with this article as being to open a new perspective on the debate around theorizing on comparative education theories. To make our point, we discuss a strategic sample of three rather commonplace comparative education approaches, and therefore do not claim comprehensive coverage of the field. On the contrary, we describe the sample as strategic, which illustrates our reasoning on how comparative education theories explain change and thereby deal with the issues of contingency. Aware of the body of "post" perspectives, we still argue that the chosen three approaches can, due to their enduring impact on the field, serve as fertile examples for illustrating our point. We analyze how the three traditions deal with contingency and use them to discuss comparative education in relation to different ontological and epistemological assumptions of change and methodological consequences. ${ }^{2}$ In this sense, our main motif is not to make normative claims

\footnotetext{
${ }^{1}$ See Paulston and Liebman (1994), Metha and Ninnes (2003), Rappleye (2015), and Silova and Rappleye (2015).

${ }^{2}$ In doing this, we continue where Nóvoa and Yariv-Mashal (2003) delimited their work, admitting that they were not writing "a research paper, nor an epistemological reflection about the field of comparative education," as we aim to do just that: present an epistemological reflection on the strategic sample.
} 
concerning which theory works best, but to point out the limitations and possibilities of different approaches. The basis of our argument is that, given their differing epistemological assumptions, different theoretical approaches to comparative education have varying potential in terms of explaining contingency. We further argue that the researchers involved must again understand themselves as significant actors in the field of which they aim to make sense.

The article is structured as follows. In the second section we discuss the question of contingency as an ontological starting point. It is possible from this vantage point to distinguish different epistemological understandings that treat contingency in different ways in the different theoretical approaches to comparative education. This is the main focus in the following part (third section) of the article. Finally, we discuss the meaning of comparative education as a contingent sense-making of contingency.

\section{Contingency as an Ontological Starting Point of Comparative Education}

We commence from the ontological assumption that the world is contingent (see Joas 2004). We aim to build an understanding of the field of comparative education on arguments attesting to the contingent nature of both the theory and the world it purports to analyze. We understand contingency as something that is possible but not necessary (Joas 2004), a finite ambiguity of events (Makropoulos 2004), an awareness or unawareness that something can always be different (Luhmann1972). These ideas are not new and, in the light of Kuhn's identification of a "paradigm shift" (Kuhn 1962), should have entered the awareness of any (social) scientist. Indeed, Giddens' (1987) theory of the double hermeneutic or the sense-making of sense-making processes also, according to Schütz (1953), points in that direction. ${ }^{3}$ In summary, our starting point in shedding light on the debate surrounding comparative education is the contingent sense-making of contingency.

Contingency entails not simply infinite possibilities but a specified infinity, in which something is neither necessary nor impossible but is a real alternative (Makropoulos 2004). Contingency is essentially about understanding available alternatives, facilitating understanding of the complex possibility structures, and the fluid construction of this reasoning. Makropolous (2004) further suggests that contingency as such does not require an awareness of different possibilities, which can be understood ex post: it means the evaluation of reality from the perspectives of necessity and possibility. Perspective relates to the subjectivity of reality; however, reality is always a constructed reality (Makropolous 2004, 375). However, as discussed in the introduction, the explanation of contingency is also contingent and as such dependent on par-

\footnotetext{
${ }^{3}$ Schuetz, in fact, did the ground work for Berger and Luckmann's (1967) social construction of reality.
} 
ticular perspectives. This relates to the process in which manifested probabilities become something understood as "necessary" through the ex post construction of meaning, as is recognized in many research strands. Koselleck ([1979] 2004) claims, in his seminal work "Futures Past," that the explanation of chance and contingency is history building: both the origin and the description of something are contingent. This is the same argument that Foucault (2002) has put forward, when claiming that discursive formations are historically contingent.

Some complexity theory related ideas are useful in conceptualizing contingency especially in terms of how the different possibilities are realized in history. Bifurcation refers to a point of time at which a contingent possibility is realized, and a branching path separates. This leads to an irreversible change as the bifurcation changes the nature of the timeline and the arrow of time that cannot be reversed (Prigogine 1997). Path dependency relates to the ideas of bifurcation and irreversibility as past choices or events permanently shape the timeline. Pierson (2000) describes the process of increasing returns, in which rather small changes at the right moment may also have far-reaching effects and create a series of events snowballing inertia and making it difficult to change course later on. Sense-making is a process involving the explanation of previous bifurcations. It "involves the ongoing retrospective development of plausible images that rationalize what people are doing" (Weick et al. 2005, 409) and is also referred to as rationalization (Castaldi and Dosi 2006). In the context of comparative education, all theory traditions have their way of explaining contingency by means of establishing what has happened. This explanation constitutes a basic understanding of how we perceive the world and, as such, affects epistemological choice in a piece of research. In the following, we incorporate this idea into perspectives on comparative education and analyze the explanatory contingencies.

\section{Comparative Education Theories and Epistemologies of Change}

In order to elaborate on the idea that the explanation of change and contingency is itself contingent, we consider epistemologies of change in a sample of theoretical approaches in the field of comparative education. In investigating these different approaches and their explanations of change in educational phenomena, we support several recent arguments which imply that particular theories involved in such disputes cannot be compared because they draw on different epistemological assumptions and as a consequence may employ different methods. As noted above, we do not attempt to cover the much larger number of theories, but instead, our sample is strategic, the aim being to illustrate our understanding of the field from this perspective. The choice of the theories in focus draws on their prominence in terms of both references and criticism in the field. 
As a systematic approach to change, we draw on the ideas of Van de Ven and Poole (1995) and their further development by Capano (2009). These researchers analyzed the epistemological starting points of organizational and policy change, which are also key aspects of comparative education. The framework consists of five ideal types of change defined through four subdimensions from the epistemological perspective:

- Key metaphor and logic sum up the main ideas behind the model in question and their key notions of change. These ideas are usually clearly stated in the theory in connection with the central concepts.

- Way of event progression refers to two factors: whether the progression is linear or nonlinear, and whether it is adaptive or cumulative. Linear causality implies the "presence of unitary sequences of events that are strictly related to each other" (Capano 2009, 11), whereas nonlinear progression refers to a sequence without strict causal links or set steps. Adaptive event progression means reacting to external change and cumulative refers to long-term change leading to a new paradigm.

- The dynamics of development as a subdimension addresses the essential issue of continuity and discontinuity. Continuity is usually connected to the idea of evolution, and discontinuity with revolution. However, given that evolutionary processes may be rapid, the key point in differentiating these two ways of thinking is whether or not there is a rupture with the past.

- Motors of change refers to the generative forces that lead to change, which include basic interactions such as competition, learning and imitation (Capano2009, 13).

Table 1 is adapted and summarized from Capano's work and presents five ideal types of change. In short, life-cycle ideal types anticipate linear event progression according to a prefigured sequence; the evolution ideal embeds a model of competitive survival, and recurrent and cumulative change based on natural selection; the dialectic approach adopts the key metaphor of conflict and progression through synthesis between opposing values or events; the teleology ideal promotes change in terms of cooperation in reaching a mutually agreed target, with discontinuous phases of goal setting, implementation and adaptation; finally chaos and complexity ideal types are based on the coevolution of different parts of the system, as well as contingent and uncertain event progression.

From our contingency vantage point we argue that the four subdimensions described above could serve to make sense of contingency. They provide the means with which to build an explanation of why things are like they are or become what they are and not something different. Our reasoning is that there is no right or wrong way of interpreting the reality, only different 


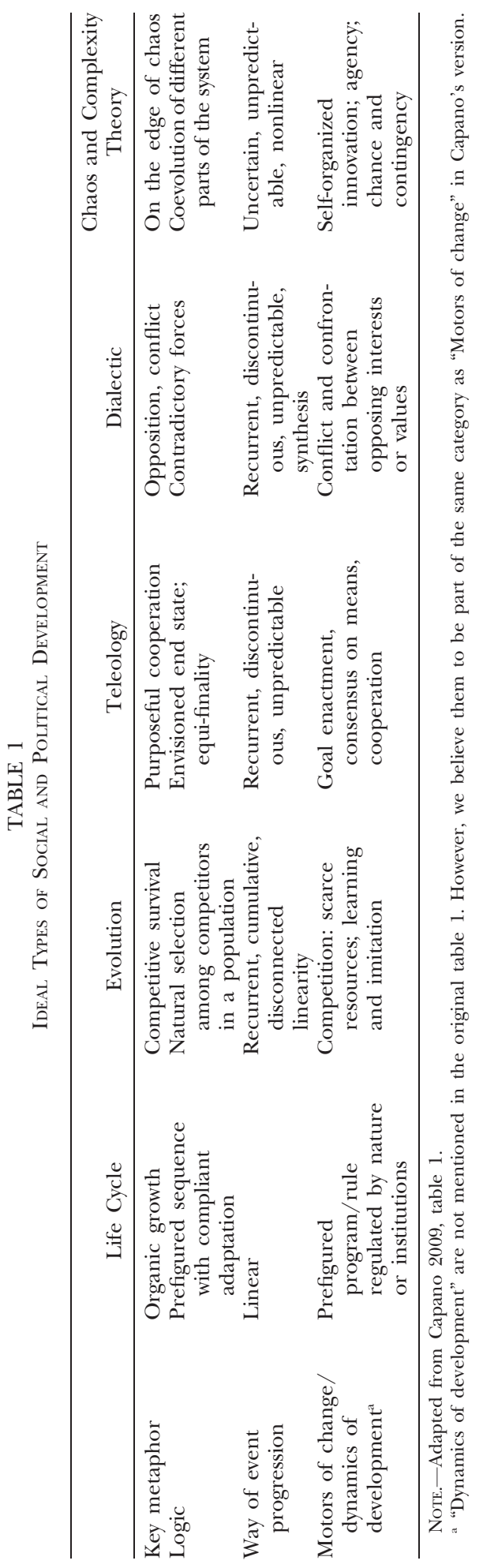

This content downloaded from 153.001.023.196 on May 03, 2018 05:59:28 AM All use subject to University of Chicago Press Terms and Conditions (http://www.journals.uchicago.edu/t-and-c). 
levels of coping with complexity. We ordered table 1 roughly by the degree of complexity. The life-cycle ideal type is linear and operates within a prefigured sequence and therefore significantly reduces the complexity of social phenomena. The process of evolution is rather simplified, although the end result is complex, whereas in the teleology ideal the end result is predicted but the process may be complex. The dialectical ideal type is clearer in terms of which parties are involved in the process, but the synthesis is unpredictable. The complexity ideal, by definition, best tolerates the complexity of social processes, but has challenges in positing simple descriptions. The less complex the approach is, the more easily it adapts to particular methods of coping with contingency, or sense-making.

Below we analyze our strategic sample of three prominent theoretical approaches in the field of comparative education from an epistemological perspective: cross-national attraction (e.g., Zymek, Steiner-Khamsi, Phillips, and colleagues), which is one deliberately selected example from policy borrowing and lending theories, the world culture approach (Ramirez, Meyer, and colleagues), and the functional-cum-configurational model drawing on systems theory (Schriewer).

\section{Cross-National Attraction}

Advocates of theories of policy borrowing and lending see these two processes as the basic operations of international influence. The borrowing and lending approach accommodates a large set of different theories and ideas, with the commonalities also broadly defined. Steiner-Khamsi (2004a, 2004b, 2012) describes how they avoid normativity (e.g., "best practices") and pursue analysis, emphasize the role of the local in the process of globalization, and also draw on policy studies in addition to comparative research.

Steiner-Khamsi (2012) separates two generations of researchers in this tradition of naming a variety of theories under the umbrella terms of borrowing and lending. According to Steiner-Khamsi, the first generation of researchers were interested in concepts such as selective policy borrowing and lending (Brian Holmes), externalization (Bernd Zymek, Jürgen Schriewer), and cross-national policy attraction (David Phillips), whereas the second generation focused on governance by numbers (Jenny Ozga), nonstate actors and postbureaucracy (Agnès van Zanten), and local meanings in important reforms (Kathryn Anderson-Levitt; Steiner-Khamsi 2012). According to SteinerKhamsi $(2012,8)$, the umbrella conceptualization is useful in its neutrality and its emphasis on the agency of both the sender and the receiver. Florian Waldow (2012) sums up the central concepts of borrowing and lending as standardization and the production of legitimacy. The former refers to the process of globalization with the help of soft governance techniques, and the latter to externalizing, in other words using an external reference to make 
internal changes, or simply borrowing from a reference society (cf. certification; Steiner-Khamsi 2004b, 203). Given that the walls are wide and the ceiling is high in this research tradition, we chose one example of a well-developed theoretical model for our analysis, strategically selected to illustrate well the plurality of epistemological starting points.

David Phillips and Kimberly Ochs developed a heuristic model to enhance understanding of policy borrowing between nations through the key metaphor of cross-national attraction (Ochs and Phillips 2004). This model has also been used recently (Whitty 2012,301 ) and below we point out equivalence with more general ideas of policy borrowing and lending. Within Capano's taxonomy, policy borrowing follows the life-cycle model quite closely.

- The key metaphor is the name of the model — cross-national attractionwhereas the logic follows a prefigured sequence in which external ideas are borrowed and adapted for national use.

- Motors of change relate to learning or imitation rather than competition. Indeed, cross-national attraction is dependent on external impulses, from investigating foreign environments, changes in public perceptions, politically motivated contrasts or the intentional scandalizing of an issue. Another important factor is the externalizing potential of the issue in question (Phillips and Ochs 2003). As Waldow (2012) shows, the legitimacy of learning from abroad (Steiner-Khamsi 2010) in the context of the borrower is an important factor, which is why borrowing can either be explicit or silent (Waldow 2009; Wermke and Höstfält 2014).

- Event progression is linear in that the borrowing process goes through four consecutive stages: cross-national attraction, decision making, implementation, internationalization/indigenization, although this is an "essentially sequential process - suggesting not causation but temporal linkage" (Phillips and Ochs 2004, 781). Borrowing and lending can also be circular, insofar as something can be lent and later borrowed (SteinerKhamsi 2010), for example, in relation to the legitimacy argument as put forward above. It is also adaptive in that the changes are a reaction to exogenous ideas: "impulses for change can inspire the search for foreign models which might solve existing or emerging potential problems" (Phillips and Ochs 2003, 453).

- The development dynamics are evolutionary: although radical changes are possible, because the change is tied to the set stages there is in-built continuity.

\section{The World Culture Approach}

The world culture approach, developed by John W. Meyer, Francisco Ramirez, and their associates at Stanford University, builds on a neo-institutional 
framework. While there are many applications of this approach, we focus only on the work by the authors mentioned, because it has been deployed more frequently in research on comparative education. The starting point is the paradoxical relationship between national-cultural differences and the global similarity of education as an institution. In the main, the approach draws on neo-institutional ideas of norm-formulated change according to which world models are diffused through international carriers (Meyer and Ramirez 2003; Ramirez 2012). Using Capano's framework, the epistemological starting points are as follows.

- The key metaphor is convergence. The logic is a transfer of models and patterns, and the actors are engaged in "enacting scripts that make sense given the triumph of some models of reality" (Meyer et al. 1997; Ramirez 2012, 423). The example of the "newly discovered island" is deployed here to point out the force of convergence (Meyer et al. 1997; cf. Rappleye 2015).

- The event progression is adaptive, as nationally exogenous expectations of what the nation-state should be push the development toward similar structural decision making. The development is continuous as there is no clear rupture with the past. Indeed, the states ${ }^{4}$ follow a similar direction, toward the institutionalization of education according to global models, but the pace differs (Ramirez 2012, 431).

- This development is enhanced by motors of change related to the increase in global communication via international organizations and stronger normative, professional and theoretical models (Meyer and Ramirez 2003, 116-17; Schriewer and Martinez 2004, 29-30; Ramirez 2012, 436). In addition, competition among nation-states is considered a key element in the diffusion of the models. This mutual competition and cooperation is at the core of explanations of isomorphism, but at the same education is the main avenue through which they are created: "Within the framework of a world society the process of becoming a nation-state and of competing with other nation-states led to the adoption of remarkably similar projects and commitments to remarkably similar technologies, such as education.” (Meyer and Ramirez 2003, 130).

In terms of the logic and motors of change the approach has teleological features. In particular, the notion of an envisioned end-state with shared

\footnotetext{
${ }^{4}$ Whereas the nation-state seems to be the main unit of action, the concept is neither simple nor legalistic. On the one hand, the explanation of the world culture approach "must go beyond 'national traditions' and situate nation-states within a broader national-state system” (Meyer and Ramirez 2003, 112). On the other hand, the nation-state "entities present themselves to the nation-state system . . . as national societies with standard modern goals and standard strategies to attain these" $(2003,115)$.
} 
norms quite closely reflects teleological explanations. ${ }^{5}$ Moreover, the motors of change are consensual, and despite global competition rely on co-operation through international organizations. The shared rules of the game in particular reflect the teleological idea of "consensus on means" (Capano 2009, 10). The direction of event progression follows teleological thinking of change as a combination of a huge set of dynamics, and although no linear causalities are presented, the equi-finality of the structure is shared. Whereas this sort of nonlinearity and self-organization is more familiar in chaos models, the world culture approach does not take a stand on how the change processes inside a nation-state operate. This is a question of the level of abstraction but on the macro level this world-culture explanation is teleological in its epistemology.

\section{The Functional-cum-Configurational Model}

The third theoretical tradition we analyze here is based on systems theory, which positions itself as a tradition in comparative education alongside the world culture approach (Schriewer 2000, 312). However, we argue that this model has abandoned the teleological features of the world culture approach. Indeed, Schriewer $(2000,2003)$ rather directly aligns with complexity theories. He does not directly present such a model, but rather contrasts earlier research and finds pathways into complex ways of thinking. For this purpose he names three theorists: Margaret Archer, Edgar Morin, and Niklas Luhmann.

- Luhmann features the most in other texts by Schriewer (2003, 36-52) in which he develops a "theoretical-cum-methodological [original emphasis]" alternative for comparative research, serving as the key metaphor for this research stream. This can be also described in terms of generalization and re-specification.

- The event progression in this model is not linear, but embedded in the "full complexity of causal networks [original emphasis]" (Schriewer 2003, 20). The basic logic is a complex combination of social and transnational processes of globalization. Change is both endogenous and exogenous, and intertwined in Luhmann's notion of self-organization $(2003,33)$. Hence, there is an "external impact and internal processing" (2003, 38).

- The core concept in understanding the dynamics of development and the motors of change is the notion of functional equivalence, in the

\footnotetext{
${ }^{5}$ This idea of a Hegelian teleology of sorts can be challenged insofar as the world culture approach has some characteristics of the dialectic ideal type. Van de Ven and Poole (1995) remind us that Hegel, together with Marx and Freud, was among the principal philosophers of the dialectic ideal type. This is undeniable, but it is fair to say that the teleological idea of the world developing in a certain direction, manifesting in an ideal, is also a key element in the thought of Hegel and Marx. The argument for the teleological, rather than the conflictual, explanation is also consistent with Arnove's (2009) description of the consensual rather than conflictive undertone of the world culture approach provided by Meyer and colleagues.
} 
Luhmannian sense, referring to dynamics "establishing relations between problems and problem solutions" (Schriewer 2003, 41). The aim is to foster empirical understanding of functional patterns, and comparison is thus an explanation of a so-called functional equivalence. The process follows steps from defining the central problems in a given context, its possible solutions, their feasibility and then understanding the configuration: which conditions and resources are necessary in order to realize this solution and what kinds of structures emerge from this and are related to the context in question. Configuration then basically refers to the use of structural examples across fields (Schriewer 1999, 58; 2003, $41,46)$. The functional patterns are restricted by path-dependencies and possibility structures, although in Schriewer's (2003, 48) words: "Structural decisions, once made, channel subsequent decisions and give rise to attendant problems." 6

In summary, Schriewer's research agenda is very close to the epistemological choices of the chaos and complexity ideal type. It may be that he is closer to complexity than to chaos, since he refers to strong explanatory frameworks, which indeed leave a lot of room for complexity, but may limit the possibilities for chaos. It is a question of whether there is room for a butterfly effect in the Luhmannian systems theory. In any case, it is clear that the functional-cumconfigurational model is quintessentially a complexity model.

\section{Conclusion and Discussion: The Paths of Contingency}

We commenced by taking on the challenge, loosely paraphrasing Paulston $(2000,363)$ of how to navigate the new spaces of knowledge in comparative education. Our main argument in this article is that understanding comparative education as a form of contingent sense-making of contingency is a first step in this endeavour. Addressing the ontological question of contingency and how it is understood, we have explored the epistemologically different approaches to change in the research field of comparative education. In this last section, we first analyze the "sense-making of contingency" and then what is "contingent sense-making" and how it has shaped the field of comparative education.

Sense-Making of Contingency: Epistemological Differences

As such, theories of comparative education cope with the issues of time and space related to educational problems. In other words, they elaborate on the relevance of the context to facilitating understanding of a particular

\footnotetext{
${ }^{6}$ Here he refers to the work of Margaret Archer and the concept of morphogenesis, an evolutionary term referring to the process through which an organism retains its form.
} 
phenomenon. Indeed, a well-structured view of time and space is a prerequisite in the analyses. We tried to take the discussion further from this debate on time and space. In an attempt to explain how comparative education as a research field handles the complexity related to time and space, we have analyzed various epistemologies of change. We claim to have pointed out how the issue of change is intrinsically intertwined with the concept of contingency, and we have now taken the first step in understanding this process of coping with the complexity inherent in the concepts of time and space based on one approach to contingency.

From our strategic sample, consisting of three quite well-employed theoretical approaches in comparative education, we discovered that disputes are organized according to the borderlines of epistemological difference with regard to change: why and how something has or has not become something else, and indeed the conditions of such a process. The different epistemological approaches, together with understanding of how much complexity a particular epistemological perspective on change can cope with, may explain some of the conflicts (table 2). In simple terms, the main problem is that the theories focus on the same aspects of the reality but differ in terms of understanding how to gain knowledge. They also have different perspectives on change. The cross-national attraction approach may heuristically tease out phases of change from an historical process, but can say little inside the black box that complexity models could open. Functional-cum-configurational approaches may claim to give a more complex perspective on microlevel change, but struggle on the macro scale. The world culture approach could cope with macro-level change, but is facing critique from the perspectives interested in the microlevel.

The varying complexity of different epistemological perspectives on change affects research methodology. For instance, proponents of the world-culture approach tend to employ a quantitative methodology. On one hand, it is an approach that allows (only) a certain level of complexity. In other words, researchers draw on a rather linear teleological understanding because applied multivariate regression models and quantitative data collection do not allow for the full explanation of many complex context-related relations that a more qualitative approach would enable. On the other hand, the success of this approach in the community engaged in research on comparative education may correlate with quite robust and developed quantitative research methodology that could be used in a wide variety of educational areas, such as counting relevant words in different syllabi or text books in terms of how often various phenomena occur in different spatial or temporal contexts (see, e.g., Baker and LeTendre 2005; Bromley et al. 2011). This comes at a price, however: complexity reduction.

The difference between the Schriewerian and the world culture approaches, for instance, is that the former is empirically more easily manageable with 


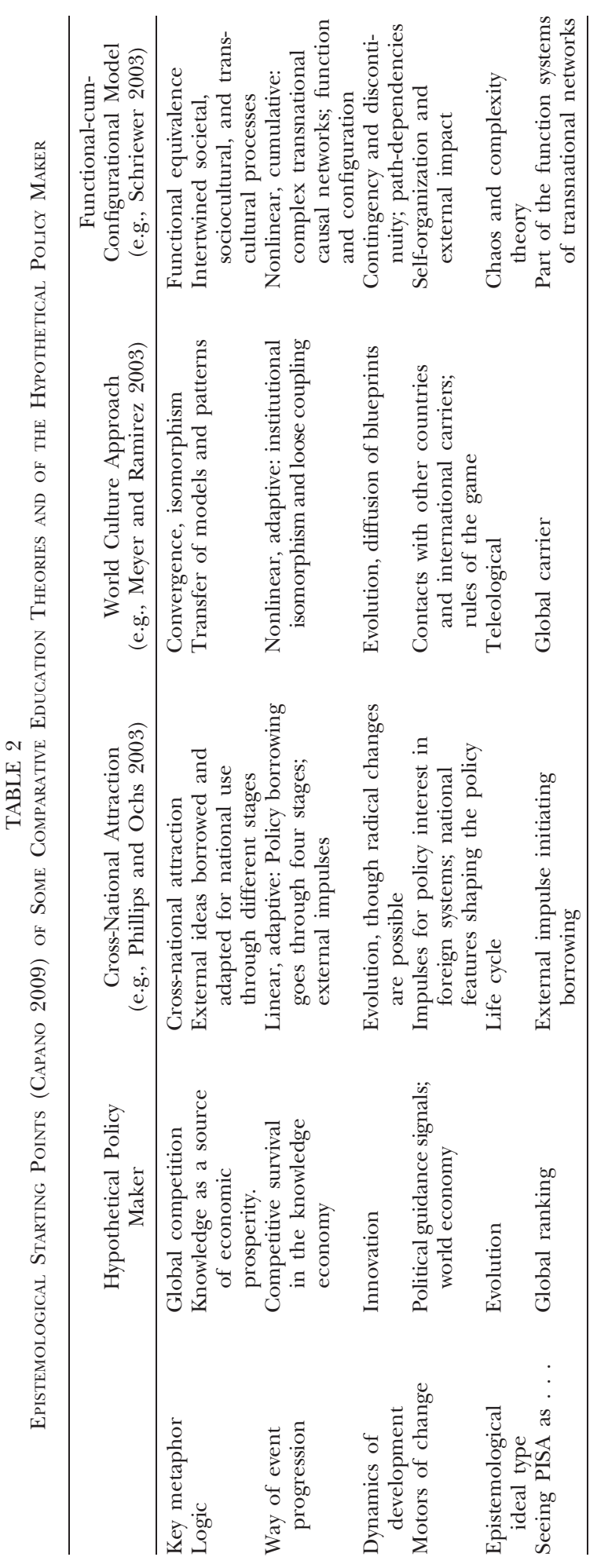

This content downloaded from 153.001.023.196 on May 03, 2018 05:59:28 AM All use subject to University of Chicago Press Terms and Conditions (http://www.journals.uchicago.edu/t-and-c). 
comparisons of only few cases, whereas the latter is based on complexityreducing quantitative multivariate models. Researchers applying the functionalcum-configurational model seem to prefer hermeneutical, interpretative (Ragin 1987), although not standardized, reasoning related to profound contextual knowledge. The difference described might even trigger mutual development and increase the relevance of the respective approaches. ${ }^{7}$

Finally, it must be emphasized that the different theoretical traditions and paradigms in social science have their strong and weak points in terms of analysis, and this is inescapable in all epistemological solutions. Words of warning come from the neighboring discipline of comparative politics, supporting our attempts to arrive at an explicit understanding of ontological and epistemological starting points in comparative education: "A key conclusion concerning the debate about the direction of comparative politics is that the field should get beyond a confrontation among broadly conceived approaches that hold false assumptions about their rivals" (Munck and Snyder 2007, 26). However, if we think here in terms of discursive strategies in order to emphasize one's own point even more, as put forward by Foucault-inspired researchers (Paulston and Liebman 1994; Metha and Ninnes 2003), it could perhaps also be that rivalry put forward also has a rationale. The reason would be that the rivalry contributes to securing their respective relevance and also development.

Alongside the research perspective, the analysis of the epistemological approaches could also be used for describing the theorizing work done by policy makers and international agency actors. The key metaphor of change, for someone devising and implementing educational reforms inside the contingent world such as the OECD's Director for the Directorate of Education and Skills Andreas Schleicher, would likely be the global competition discourse (Henry et al. 2001; Rinne et al. 2004; Grek 2009). In such an understanding, PISA ranking could legitimately reflect the position of a nation in the contest centered on the knowledge economy (see Hopmann 2006). There are numerous other possible perspectives, but with this intentionally provocative example we want to raise the problems of distance between policy-making and complex research ideas (cf. Nóvoa and Yariv-Mashal 2003). If a policy maker was better informed regarding the more complex views in comparative education, he or she might see new possibilities beyond existing structures. Table 2, as the finishing line of our "sense-making of contingency" part of the argument, summarizes the perspectives discussed in this article (including that of the hypothetical policy maker) in relation to Capano's epistemologies of change.

\footnotetext{
${ }^{7}$ A possible piece of evidence for this argument might be the frequent and fertile communication of the researchers involved: at the frequent symposia organized by Jürgen Schriewer on the Comparative and International Education Society (CIES) conferences including, e.g., Franciso Ramirez, but also Iveta Silova, Barbara Schulte, Steven Carney or Jeremy Rappleye, or also Schriewer's special issues and edited books (Schriewer 2003, 2012) bringing together the different approaches analyzed here.
} 
Contingent Sense-Making: Perspectives on Comparative Education

We have pointed out the inherent contingency in theories of comparative education that revives various early arguments. ${ }^{8}$ Drawing on our understanding of the contingency of comparative education sense-making, we conclude with three critical points: the path-dependency in comparative education, theoretical challenge in post-structuralist approaches, and the solace in sensemaking.

If we take the idea of contingency and more accurately the idea of pathdependency as a serious description of our world, comparative education does not escape these features either. Throughout the article, we have concentrated on three prominent theoretical traditions of policy borrowing and lending, world culture and functional-cum-configurational model. Each of these traditions have created their own path-dependencies in the field of comparative education. In addition to their commonalities in terms of theoretical presuppositions, which are strongest in the two latter and more open in the case of borrowing and lending, these traditions have created important flag terminology for understanding the comparative education debate. Following the idea of increasing returns (Pierson 2000) one could argue that, notwithstanding the heavy criticism leveled toward the world culture approach for instance, these approaches have gained insurmountable prominence and a reference point for theorizing.

In the post-structural tradition, the building of a theoretical umbrella is difficult if not impossible, given its self-reflective nature. In more colloquial terms, the question would be which is the household theory of post-structuralist comparative education? The self-reflective nature of the post-structural approaches is aware of the contingent nature of sense-making, but for this reason also bears a difficulty in forming a broader theoretical base for making claims on comparative education. One could also argue that post-structuralist approaches draw on classical theories developed outside the comparative education sphere (e.g., Ninnes and Burnett 2003), which bring out the open question of whether or not there should be theory building that is focused only on comparative education.

The contingency of sense-making also grants us some solace insofar as it helps to understand that theory need not be taken so seriously (see Ninnes 2008), because its contingent nature is inescapable. For discussion's sake, we argue that a bad theory is better than no theory at all. In this regard, the approaches inclined to "modernist rule-making" (Paulston 2000) should become more aware of the contingent nature of their sense-making and the approaches at risk of taking "poststructuralist nihilism” (Paulston 2000)

\footnotetext{
${ }^{8}$ See, e.g., the early arguments that were put forward by Schütz (1953), Kuhn (1962), Berger and Luckman (1967), and Giddens (1987).
} 
should be bolder in building theoretical ideas on contingency. ${ }^{9}$ For achieving this, an epistemological understanding of change in the field must be the starting point.

\section{References}

Ahmed, Sara. 2000. Strange Encounters. Embodied Others in Post-Coloniality. London: Routledge.

Arnove, Robert F. 2009. "World-Systems Analysis and Comparative Education in the Age of Globalisation." In International Handbook of Comparative Education, ed. Robert Cowen and Andreas M. Kazamias. Dordrecht: Springer.

Baker, David P., and Gerald K. LeTendre. 2005. National Differences, Global Similarities: World Culture and the Future of Schooling.. Stanford, CA: Stanford University Press.

Berger, Peter L., and Thomas Luckmann. 1967. The Social Construction of Reality: A Treatise in the Sociology of Knowledge. New York: Random House.

Broadfoot, Patricia. 2003. "Post-Comparative Education?" Comparative Education 39 (3): 275-77.

Bromley, Patricia, John W. Meyer, and Francisco O. Ramirez. 2011. "The Worldwide Spread of Environmental Discourse in Social Studies, History, and Civics Textbooks, 1970-2008." Comparative Education Review 55 (4): 517-45.

Capano, Giliberto. 2009. "Understanding Policy Change as an Epistemological and Theoretical Problem." Iournal of Comparative Policy Analvsis: Research and Practice 11 (1): 7-31.

Carney, Stephen. 2009. "Negotiating Policy in an Age of Globalization: Exploring Educational 'Policyscapes' in Denmark, Nepal, and China." Comparative Education Review 53 (1): 63-68.

Castaldi, Carolina, and Giovanni Dosi. 2006. "The Grip of History and the Scope for Novelty: Some Results and Open Questions on Path Dependence in Economic Processes." In Understanding Change: Models, Methodologies, and Metaphors, ed. Andreas Wimmer and Reinhart Kossler. Houndmills: Palgrave Macmillan, 99-128.

Cowen, Robert. 2002. "Moments of Time: A Comparative Note." History of Education 31 (5): 413-21.

Cowen, Robert. 2009. "Editorial Introduction: New Thinking." In International Handbook of Comparative Education, ed. Robert Cowen and Andreas M. Kazamias. Dordrecht: Springer.

Djeluic, Marie-Laure, and Kerstin Sahlin-Andersson. 2006. "Introduction: A World of Government Regulation: The Rise of Transnational Regulation.” In Transnatinal Governance: Institutional Dynamics of Regulation, ed. M.-L. Djeluic and K. SahlinAndersson. Cambridge: Cambridge University Press.

Foucault, Michel. 2002. The Archaeology of Knowledge. London: Routledge.

Giddens, Anthony. 1987. Social Theory and Modern Sociology. Cambridge: Polity.

Grek, Sotiria. 2009. "Governing by Numbers: The PISA 'Effect' in Europe.” Lournal of Education Policy 24 (1): 23-37.

\footnotetext{
${ }^{9}$ Prigogine (1997) argued that in order to bridge the gap between classical and modern physics, both should pay more attention to probabilities rather than certainties.
} 
Henry, Miriam, Bob Lingard, Fazal Rizvi, and Sandra Taylor. 2001. The OECD, Globalisation and Education Policy. Oxford: Pergamon.

Hopmann, S. 2006. "Im Durchschnitt Pisa oder alles bleibt schlechter" [In average PISA or everything stays worse]. In Lehrpläne und Bildungsstandards. Was Schüler und Schülerinnen lernen sollen [Curricula and Educational Standards. What Pupils Have to Learn], ed. L. Criblez, P. Gautschi, P. Hirt Monico, and H. Messner. Bern: HEP.

Joas, Hans. 2004. "Morality in an Age of Contingency.” Acta Sociologica 47 (4): 392-99.

Jokila, Suvi, Johanna Kallo, and Risto Rinne. 2015. Comparing Times and Spaces: Historical, Theoretical and Methodological Approaches to Comparative Education. Jyväskylä: FERA.

Joseph, C. 2009. "Postcoloniality and Ethnography: Negotiating Gender, Ethnicity, and Power." Race Ethnicits and Education 12 (1): 11-15.

Kallo, Johanna. 2012. "Temporal Comparisons and Change in Higher Education." In Koulutuksen Yhteiskunnallinen Ymmärrys, ed.J. Kivirauma, A.Jauhiainen, P. Seppänen, and Tuuli Kaunisto. Jyväskylä: FERA.

Kazamias, Andreas M. 2009. "Comparative Education: Historical Reflections." In International Handbook of Comparative Education, ed. R. Cowen and A. M. Kazamias. Dordrecht: Springer.

Kettunen, Pauli. 2011. "The National Welfare State as Transnational Historical Costruction." In Beyond the Welfare State Models, ed. Klaus Petersen and Pauli Kettunen. Cheltenham: Edward Elgar.

Koselleck, Reinhart. (1979) 2004. Future Past. On the Semantics of Historical Time. New York: Columbia University Press.

Kuhn, Thomas S. 1962. The Structure of Scientific Revolutions. Chicago: University of Chicago Press.

Lahelma, Elina, and Tuula Gordon. 2010. "Comparative and Cross-cultural Ethnography." In Restructuring the Truth of Schooling - Essays on Discursive Practices in the Sociology and Politics of Education, ed. J. Kauko, R. Rinne, and H. Kynkäänniemi. Jyväskylä: FERA.

Larsen, Marianne A., and Jason Beech. 2014. "Spatial Theorizing in Comparative and International Education Research.” Comparative Education Review 58 (2): 191-214.

Lawn, Martin, and Jenny Ozga. 2012 "Making Good Progress? Governing by Inspection: A Post-Comparative Approach.” In Koulutuksen Yhteiskunnallinen Ymmärrys. Social Perspectives on Education, ed. J. Kivirauma, A. Jauhiainen, P. Seppänen, and T. Kaunisto. Turku: Finnish Educational Research Association.

Luhmann, Niklas. 1972. "Weltzeit und Systemgeschichte. Über Beziehungen Zwischen Zeithorizonten und Sozialen Strukturen Gesellschaftlicher Systeme" [World Time and System History. On Relations of Horizons of Time and Social Structures of Societal Systems]. In Soziologie und Sozialgeschichte [Sociology and Social History], ed. P. C. Lutz. Opladen: Westdeutscher.

Lundahl, Christian, and Florian Waldow. 2009. "Standardisation and 'Quick Languages': The Shape Shifting of Standardised Measurement of Pupil Achievement in Sweden and Germany." Comparative Education 45 (3): 365-85.

Makropoulos, Michael. 2004. "Kontingenz. Aspekte einer Theoretischen Semantik der Moderne" [Contingency. Investigating theoretical semantics of modernity]. European Journal of Teacher Sociology 45 (3): 369-99. 
Marginson, Simon, and Gary Rhoades. 2002. "Beyond National States, Markets, and Systems of Higher Education: A Glonacal Agency Heuristic." Higher Education 43 (3): 281-309.

Metha, Sonia, and Peter Ninnes. 2003. "Postmodernism Debates and Comparative Education: A Critical Discourse Analysis." Comparative Education Review 47 (2): 238 55.

Meyer, John W., John Boli, George M. Thomas, and Francisco O. Ramirez. 1997. "World Society and the Nation-State." American Journal of Sociology 103 (1): 144-81.

Meyer, John W., and Francisco O. Ramirez. 2003. "The World Institutionalization of Education.” In Discourse Formation in Comparative Education, ed. Jürgen Schriewer. Frankfurt am Main: Peter Lang.

Munck, Gerardo L., and Richard Snyder. 2007. "Debating the Direction of Comparative Politics: An Analysis of Leading Journals." Comparative Political Studies 40 (1): 5-31.

Ninnes, Peter. 2008. "Fear and Desire in Twentieth Century Comparative Education." Combarative Education 44 (3): 345-58.

Ninnes, Peter, and Gregory Burnett. 2003. "Comparative Education Research: Poststructuralist Possibilities." Comparative Education 39 (3): 279-97.

Nóvoa, António, Luís Miguel Carvalho, António Carlos Correia, Ana Isabel Madeira, and Jorge Ramos de Ó. 2003. Educational Knowledge and Its Circulation. Historical and Comparative Approaches of Portuguese-Speaking Countries. Lisbon: EDUCA.

Nóvoa, António, and Tali Yariv-Mashal. 2003. "Comparative Research in Education: A Mode of Governance or a Historical Journey?” Comparative Education 39: 423-39.

Ochs, Kimberly, and David Phillips. 2004. "Processes of Educational Borrowing in Historical Context." In Educational Policy Borrowing: Historical Perspectives, ed. David Phillips and Kimberly Ochs. Oxford: Symposium.

Paulston, Rolland. 1999. "Mapping Comparative Education after Postmodernity." Race, Ethnicity, and Education 12 (1): 11-15.

Paulston, Rolland. 2000. "Imagining Comparative Education: Past, Present, Future." Compare 30 (3): 353-67.

Paulston, Rolland, and Martin Liebman. 1994. "An Invitation to Postmodern Social Cartography." Comparative Education Review 38 (2): 215-32.

Phillips, David, and Kimberly Ochs. 2003. "Processes of Policy Borrowing in Education: Some Explanatory and Analytical Devices." Comparative Education 39 (4): 45161.

Phillips, David, and Kimberly Ochs. 2004. "Researching Policy Borrowing: Some Methodological Challenges in Comparative Education.” British Educational Research Lournal 30 (6): 773-84.

Pierson, Paul. 2000. "Increasing Returns, Path Dependence, and the Study of Politics." American Political Science Review 94 (2): 251-67.

Popkewitz, Thomas S., ed. 2005. "Introduction." In Inventing the Modern Self and John Dewey: Modernism and the Traveling of Pragmatism in Education. New York: Palgrave Macmillan, 3-38.

Prigogine, Ilya. 1997. The End of Certainty. Time, Chaos, and the New Laws of Nature. New York: Free Press. 
Ragin, Charles C. 1987. The Comparative Method. Moving beyond Qualitative and Quantitative Strategies. Berkeley: University of California Press.

Ramirez, Francisco O. 2012. "The World Society Perspective: Concepts, Assumptions, and Strategies." Comparative Education 48 (4): 423-39.

Rappleye, Jeremy 2015. "Revisiting the Metaphor of the Island: Challenging 'World Culture' from an Island Misunderstood." Globalisation. Societies and Education 13 (1): 58-87.

Rinne, Risto, Johanna Kallo, and Sanna Hokka. 2004. "Too Eager to Comply? OECD Education Policies and the Finnish Response." European Educational Research Journal 3 (2): 454-85.

Robertson, Susan L., Xavier Bonal, and Roger Dale. 2002. "GATS and the Education Service Industry: The Politics of Scale and Global Reterritorialization." Comparative Education Review 46 (4): 472-95

Schriewer, Jürgen. 1999. "Coping with Complexity in Comparative Methodology: Issues of Social Causation and Processes of Macro-Historical Globalisation." In Learning from Comparing. New Directions in Comparative Educational Research, ed. R. Alexander, P. Broadfoot, and D. Phillips. Oxford: Symposium.

Schriewer, Jürgen. 2000. "World System and Interrelationship Networks. The Internationalization of Education and the Role of Comparative Inquiry." In Educational Knowledge. Changing Relationships between the State, Civil Society, and the Educational Community, ed. Thomas S. Popkewitz. Albany: State University of New York Press.

Schriewer, Jürgen. 2003. "Comparative Education Methodology in Transition: Toward a Science of Complexity?" In Discourse Formation in Comparative Education, ed. Iürgen Schriewer. Frankfurt am Main: Peter Lang.

Schriewer, Jürgen. 2012. "Reconceptualizing the Global/Local Nexus: Meaning Constellations in the World Society." Comparative Education 48 (4): 411-22.

Schriewer, Jürgen, and Carlos Martinez. 2004. "Constructions of Internationality in Education." In The Global Politics of Educational Borrowing and Lending, ed. Gita Steiner-Khamsi. New York: Teachers College.

Schütz, Alfred. 1953. "Common-Sense and Scientific Interpretation of Human Action." Philosophy and Phenomenological Research 14 (1): 1-38.

Silova, Iveta, and Jeremy Rappleye. 2015. "Beyond the World Culture Debate in Comparative Education: Critiquess, Alternatives and a Noisy Conversation." Globalisation. Societies and Education 13 (1): 1-7.

Simola, Hannu, Jaakko Kauko, Janne Varjo, Mira Kalalahti, and Fritjof Sahlström. 2017. Dynamics in Education Politics. Understanding and Explaining the Finnish Case. London: Routledge.

Steiner-Khamsi, Gita. 2004a. "Introduction. Globalization in Education: Real or Imagined?" In The Global Politics of Educational Borrowing and Lending, ed. Gita Steiner-Khamsi. New York: Teachers College.

Steiner-Khamsi, Gita. 2004b. "Blazing a Trail for Policy Theory and Practice." In The Global Politics of Educational Borrowing and Lending, ed. Gita Steiner-Khamsi. New York: Teachers College.

Steiner-Khamsi, Gita. 2010. "The Politics and Economics of Comparison." Comparative Education Review 54 (3): 323-42. 
Steiner-Khamsi, Gita. 2012. "Understanding Policy Borrowing and Lending: Building Comparative Policy Studies." In Policy Borrowing and Lending in Education. World Yearbook of Education 2012, ed. Gita Steiner-Khamsi and Florian Waldow. London: Routledge.

Steiner-Khamsi, Gita, and Ines Stolpe. 2006. Educational Import. Local Encounters with Global Forces in Mongolia. New York: Palgrave Macmillan.

Tikly, Leon. 2001. "Globalisation and Education in the Postcolonial World: Toward a Conceptual Framework." Comparative Education 37 (2): 151-71.

Van de Ven, Andrew H., and Marshall S. Poole. 1995. "Explaining Development and Change in Organizations." Academv of Management Review 20 (3): 510-40.

Waldow, Florian. 2012. "Standardisation and Legitimacy: Two Central Concepts in Research on Educational Borrowing and Lending." In Policy Borrowing and Lending in Education. World Yearbook of Education 2012, ed. Gita Steiner-Khamsi and Florian Waldow. London: Routledge.

Weick, Karl E., Kathleen M. Sullivan, and David Obstfeld. 2005. "Organizing and the Process of Sense Making.” Organization Science 16 (4): 409-21.

Wermke, Wieland, and Gabriella Höstfält. 2014. "Silent and Explicit Borrowing of International Policy Discourses. The Case of the Swedish Teacher Education Reforms of 2001 and 2011." Education Inquiry 5 (4): 445-60.

Werner, Michael, and Benedict Zimmermann. 2006. "Beyond Comparison: 'Histoire Croisée' and the Challenge of Reflexivity." History and Theory 45 (1): 30-50.

Whitty, Geoff. 2012. "Policy Tourism and Policy Borrowing in Education: A TransAtlantic Case Study." In World Yearbook of Education 2012: Policy Borrowing and Lending in Education, ed. Gita Steiner-Khamsi and Florian Waldow. London: Routledge. 